\title{
The research of the electrical properties of thick-film electrodes on piezoceramics in special conditions
}

\author{
Ye.Ya. Telnikov, I.O. Khmara, O.M. Nedbailo (0000-0003-1416-9651), O.G. Chernyshyn (0000-0001-7702-894X) \\ The State Enterprise "Engineering Center «Drying»" Institute of Engineering Thermophysics of NAS of Ukraine, \\ str. Bulakhovskogo, 2, Bldg. 2, Kyiv, 03164, Ukraine \\ Tel.: +380444240279, tel./fax +380444243283 \\ E-mail:icsushka@gmail.com
}

Article info: received 18.02.2019, revised 01.03.2019, accepted 29.03.2019

Telnikov, Ye.Ya., Khmara, I.O., Nedbailo, O.M., Chernyshyn, O.G. (2019) The research of the electrical properties of thick-film electrodes on piezoceramics in special conditions 1(42), doi: 10.26909/csl.1.2019.4

The results of the study of the electrophysical properties of metal-ceramic compositions based on nickel boride depending on the composition, heat treatment conditions and after exposure to mixed reactor radiation (neutrons and $\gamma$-radiation) are presented. A method of metallization of piezoelectric ceramics based on materials developed using thick-film technology is proposed. The paper discusses the results of the study of physicochemical processes occurring during the heat treatment of films and their influence on the properties of piezoceramics.

The advantages of thick-film technology, widely used in microelectronics, are well known, but the use of noble metals causes a number of serious production problems associated with their high cost, the need for waste management and reporting; Operational disadvantages include instability of properties (especially under mixed reactor irradiation conditions) due to the high diffusion coefficients of these metals (especially silver) and their leaching when soldering the leads.

This work is devoted to the study of the electrophysical properties of pastes for thick-film metallization of piezoceramics, which do not contain extremely scarce and noble metals, burned in air, are not inferior in their operational parameters to pastes based on silver-palladium alloy and are intended to replace the latter.

Key words: metal-ceramic compositions, piezoceramics, heat treatment of films.

\section{Исследование электрофизических свойств толстопленочных электродов на пьезокерамике в особых условиях}

\author{
Е.Я. Тельников, И.А. Хмара, А.Г. Чернышин, А.Н. Недбайло \\ Государственное предприятие «Инженерный центр «Суика»» Института технической теплофизики \\ НАН Украины, Киев, Украина
}

Приведены результаты исследования электрофизических свойств металлокерамических композиций на основе борида никеля в зависимости от состава, условий термообработки и после воздействия смешанного реакторного излучения (нейтронов и $\gamma$-излучения).

Предложен способ металлизации пьезокерамики на основе разработанных материалов с использованием толстопленочной технологии.

В работе обсуждаются результаты исследования физико-химических процессов, протекающих при термообработке пленок и их влияния на свойства пьезокерамики.

\author{
Введение \\ В современной радиоэлектронной аппаратуре в \\ блоках вторичного электропитания широко исполь- \\ зуются пьезотрансформаторы.
}

Конструкция пьезотрансформатора проста - это пластина из поляризованной пьезокерамики с металлизацией определенных участков ее поверхности, выполняющих роль первичных и вторичных электродов. При подаче электрического сигнала 
за счет обратного пьезоэффекта в пластине возникают механические колебания, которые на выходных электродах в результате прямого пьезоэффекта преобразуются во вторичный электросигнал. Параметры трансформаторов легко варьируются геометрией расположения электродов на пластине. Плоская конструкция пьезотрансфрматора идеальна для конструктивного сочетания с электронной частью схемы, выполняемой по планарной технологии. Отсутствие обмоток и связанного с этим расхода меди, устойчивость к коротким замыканиям, пожаробезопасность, технологичность изготовления - далеко неполный перечень достоинств пьезотрансформаторов.

При выборе материала для электродов и способа нанесения на пьезокерамику учитывается комплекс технологических, эксплуатационных и экономических показателей. В настоящее время оптимальным покрытием для электродов пьезотрансформаторов зарекомендовали себя толстые пленки на основе сплава серебро-палладий. Толстопленочная технология состоит в нанесении методом трафаретной печати паст из диспергированных компонентов с последующей термообработкой, которая в рассматриваемом случае проводится без применения какой-либо защитной среды. Достоинства толстопленочной технологии, широко использующейся в микроэлектронике, хорошо известны, однако применение благородных металлов обусловливает ряд серьезных производственных проблем, связанных с их высокой стоимостью, необходимостью утилизации отходов и отчетности; к эксплуатационным недостаткам относится нестабильность свойств (особенно в условиях смешанного реакторного облучения) из-за высоких коэффициентов диффузии этих металлов (особенно серебра) и их выщелачивания при пайке выводов.

Данная работа посвящена исследованию электрофизических свойств паст для толстопленочной металлизации пьезокерамики, которые не содержат в своем составе остродефицитных и благородных металлов, обжигаются в воздушной среде, не уступают по своим эксплуатационных параметрам пастам на основе сплава серебро-палладий и предназначены для замены последних.

\section{Материалы и методы исследования}

Металлокерамические композичионные материаль для металлизаџии пьезокерамики. Для металлизации пьезокерамики были выбраны пасты на основе борида никеля $\left(\mathrm{Ni}_{3} \mathrm{~B}\right)$, которые успешно используются при изготовлении коммутационной топологии гибридных интегральных схем.

В состав пасты кроме функциональной фазы, составляющей основу пасты, входят стеклосвязующее, органическое связующее и определенные добавки для корректировки технологических и эксплуатационных характеристик.

Органика предназначена только для придания пасте требуемой консистенции и выгорает три термообработке. При ее выборе, однако, следует учитывать характер физико-химических процессов, протекающих в пленке на стадии ее формирования. В исследуемых составах в качестве органического связующего применены 3 - 5 \%-ные растворы этилцеллюлозы в терпинеоле.

Стеклосвязующее, которое вводится в пасту в виде дисперсного порошка, выполняет роль постоянной связки - оно консолидирует пленку и обеспечивает ее адгезию к подложке. Для реализации этих функций температура термообработки должна превышать температуру размягчения стекла. Частицы стекла переходят в жидкое состояние, коагулируют и, смачивая частицы функциональной фазы, заполняют промежутки между ними.

При выборе стеклосвязующего основное внимание уделялось следующим вопросам:

- согласованию значений линейного коэффициента термического расширения функциональной фазы, стекла и подложки;

- хорошему смачиванию жидким стеклом функциональной фазы и подложки;

- физико-химической совместимости стекла и функциональной фазы.

В качестве стеклосвязующего для паст на основе $\mathrm{Ni}_{3} \mathrm{~B}$ было опробовано несколько серийно выпускаемых стекол. Свойства пленок при содержании стекла в пасте 3 \% (мас.) представлены в таблице 1. Измерения проводились по стандартным методикам.

Таблица 1.

Свойства пленок на основе $\mathrm{Ni}_{3} \mathrm{~B}$ с различными стеклосвязующими на поверхности пьезокерамики

\begin{tabular}{|c|c|c|c|c|c|c|c|c|}
\hline Марка стекла & С-82-3 & Сd-22-В & Ч-48-2 & С-660 & C-41-1 & C-551 & C-279 & C-1131 \\
\hline Электросопротивление, Ом/ & 0,04 & 0,03 & $>10^{12}$ & 0,04 & $>10^{12}$ & 0,05 & 0,02 & 0,02 \\
\hline Адгезия* & хорош. & удовл. & плохая & плохая & плохая & плохая & хорош. & удовл. \\
\hline
\end{tabular}

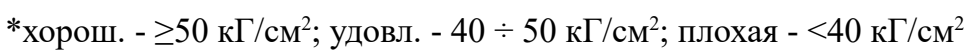


Из приведенных результатов следует, что лучшими характеристиками обладают пленки, в которых в качестве стеклосвязующего используется стекло С-279. Это - свинцовоборосиликатное стекло с температурой размягчения $\sim 610{ }^{\circ} \mathrm{C}$.

В таблице 2 представлены результаты исследования влияния содержания стекла С-279 на свойства проводниковых пленок на основе $\mathrm{Ni}_{3} \mathrm{~B}$, из которых следует, что оптимальным количеством стекла, обеспечивающим хорошую адгезию при высокой электропроводности, является 3 \% (мас.).

Процессы окисления при термообработке пленок на основе неблагородных металлов играют важную роль при формировании их свойств, и исследование этих процессов необходимо при оптимизации режимов термообработки. В данной работе такое исследование проводилось посредством дифференциально-термического и рентгенофазового анализов. Использовались дериватограф системы в авторстве Ф. Паулик, И. Паулик, А. Эрдеи и дифрактометр ДРОН - 0,5. Установлено, что в пленках на основе $\mathrm{Ni}_{3} \mathrm{~B}$ при их термообработке протекают соответственно следующие реакции

$$
\left(k \mathrm{Ni}_{3} \mathrm{~B}\right)+4 \mathrm{Ni}_{3} \mathrm{~B}+3 \mathrm{O}_{2}=12 \mathrm{Ni}+2 \mathrm{~B}_{2} \mathrm{O}_{3}+\left(k \mathrm{Ni}_{3} \mathrm{~B}\right) .
$$

Наличие равных членов в скобках в обеих частях реакций отражает тот факт, что реакции при термообработке проходят не до конца. По результатам измерения приращения массы в экспериментах, моделирующих реальный режим термообработки, определялись коэффициенты $k$ в уравнениях реакций, что давало возможность количественной оценки фазового состава пленок после термообработки. Следует отметить, что образование Ni в результате окисления $\mathrm{Ni}_{3} \mathrm{~B}$ подтверждается не только результатами рентгенофазового анализа, но и измерениями магнитных свойств [1]. Отсутствие оксидов никеля в продуктах реакции связано с защитным эффектом легкоплавкого $\mathrm{B}_{2} \mathrm{O}_{3}$, обволакивающего частицы $\mathrm{Ni}_{3} \mathrm{~B}$ - Ni. В результате установлено, что при оптимальных режимах термообработки (820 - $840{ }^{\circ} \mathrm{C}, 5$ - 10 мин.) часть функциональной фазы, взаимодействующая с кислородом, составляет для $\mathrm{Ni}_{3} \mathrm{~B}-20 \div 22 \%$.

Интенсивность процесса окисления при термообработке зависит от дисперсности порошка функциональной фазы. Оптимальная дисперсность порошка $\mathrm{Ni}_{3}$ В составляет $1900 \mathrm{~cm}^{2} /$ г.

При температурах вблизи $820^{\circ} \mathrm{C}$, как следует из приведенных результатов, формируются пленки с высокой электропроводностью и хорошей адгезией. При увеличении времени выдержки адгезия улучшается, но растет и электросопротивление. Оптимум $5 \div 10$ минут при максимальной температуре.

В таблице 3 представлены характеристики пленок, полученных при различных температурах термообработки (время выдержки при максимальной температуре - 10 мин.).

\section{Результаты и их обсуждение}

Испытания пьезотрансформаторов. В связи с тем, что в данной работе, в отличие от обычных задач по металлизации керамики, подложкой является пьезоматериал с повышенными требованиями к его

Таблица 2.

Свойства пленок на основе $\mathrm{Ni}_{3} \mathrm{~B}$ с различным содержанием стекла С-279

\begin{tabular}{|c|c|c|c|c|c|c|c|c|}
\hline Содержание стекла, мас. \% & 1 & 2 & 3 & 5 & 7 & 10 & 20 & 30 \\
\hline Электросопротивление, Ом/口 & 0,2 & 0,06 & 0,02 & 0,03 & 0,04 & 0,11 & 0,5 & 1 \\
\hline Адгезия* & плохая & удовл. & хорош. & хорош. & хорош. & хорош. & хорош. & хорош. \\
\hline
\end{tabular}

Таблица 3.

Свойства пленок на основе $\mathrm{Ni}_{3} \mathrm{~B}$, полученных при различных температурах термообработки

\begin{tabular}{|c|c|c|c|c|c|c|}
\hline$t,{ }^{\circ} \mathrm{C}$ & 760 & 780 & 800 & 820 & 840 & 860 \\
\hline Электросопротивление, Ом/口 & 0,15 & 0,1 & 0,03 & 0,02 & 0,01 & 0,01 \\
\hline Адгезия & удовл. & удовл. & хорош. & хорош. & хорош. & хорош. \\
\hline
\end{tabular}


электронным свойствам, качество покрытия определяется не только его электропроводностью и адгезией, но и влиянием на диэлектрические свойства пьезокерамики. В таблице 4 представлены результаты измерения угла диэлектрических потерь пьезокерамики и ее емкости между входными электродами, изготовленными из паст на основе $\mathrm{Ag}$ и $\mathrm{Ni}_{3} \mathrm{~B}$, причем для корректности сравнения электроды из различных материалов были нанесены на пластины из одной и той же партии.

Из приведенной таблицы следует, что параметры пьезокерамики с электродами на основе Ag и $\mathrm{Ni}_{3} \mathrm{~B}$ сопоставимы между собой.

Исследование влияния смешанного реакторного излучения на электрофизические свойства толстопленочных электродов пьезотрансформаторов. Опыт эксплуатации атомных энергетических установок в нормальных и нестандартных условиях свидетельствует о том, что элементы систем управления, защиты, контроля, измерения различных параметров должны, кроме обычных требований, удовлетворять еще и требованиям достаточной надежности и работоспособности в поле смешанного реакторного излучения (нейтронное и $\gamma$-излучение) $[1,2]$.

Современные интегральные схемы, элементы этих схем, элементы вычислительной техники и блоков управления состоят из сложных легированных материалов, с большим количеством подрешеток, с сложной молекулярной и кристаллической структурой. Теоретический анализ поведения подобных систем в поле излучения практически невозможен, т.к. в механизме радиационного воз- действия одновременно будут участвовать налетающие частицы корпускулярного излучения, вторичные атомы, выбитые из кристаллической решетки частицами первичного излучения. Образование радиационных дефектов носит каскадный характер и является термодинамически неравновесным процессом, зависящим от температуры. Дефекты и радиогенные примеси влияют на зонную структуру полупроводниковых веществ, на теплофизические, электрофизические и механические свойства. В общем случае полупроводники, металлы и диэлектрики под действием облучения изменяют концентрацию носителей, электропроводность, электрическое сопротивление, изменяются диэлектрические свойства, фоточувствительность и т.д., что приводит, в конечном итоге, к изменению режима работы блоков, систем, механизмов в целом и к выходу из строя при придельных изменениях основных параметров управляющих систем.

Измерения должны выполняться дистанционно без извлечения образцов из зоны облучения. Для выполнения подобных измерений на реакторе ИР200 разработана специальная схема дистанционного измерения электрофизических свойств проводников, резисторов и диэлектриков.

В работе выполнены измерения $R, C, \operatorname{tg} \delta$ испытуемых образцов до облучения, во время облучения и после, в зависимости от мощности излучения и длительности экспозиции.

В качестве объектов исследований были выбраны образцы пьезотрансформаторов с металлизацией из металлокерамических проводниковых композиций на основе $\mathrm{Ni}_{3} \mathrm{~B}$.

Таблица 4.

Свойства пьезокерамики после нанесения электродов из различных материалов

\begin{tabular}{|c|c|c|c|c|c|}
\hline \multicolumn{6}{|c|}{ Электроды из паст на основе } \\
\hline \multicolumn{3}{|c|}{$\mathrm{Ag}-\mathrm{Pd}$} & \multicolumn{3}{|c|}{$\mathrm{Ni}_{3} \mathrm{~B}$} \\
\hline № & $\mathrm{C}_{\mathrm{BX}}, \Pi \Phi$ & $\operatorname{tg} \delta$ & № & $\mathrm{C}_{\mathrm{BX}}, \Pi \Phi$ & $\operatorname{tg} \delta$ \\
\hline 1 & 896 & 0,012 & 11 & 910 & 0,014 \\
\hline 2 & 946 & 0,005 & 12 & 830 & 0,017 \\
\hline 3 & 969 & 0,010 & 13 & 1019 & 0,009 \\
\hline 4 & 884 & 0,007 & 14 & 842 & 0,012 \\
\hline 5 & 951 & 0,005 & 15 & 1040 & 0,021 \\
\hline 6 & 915 & 0,010 & 16 & 904 & 0,018 \\
\hline 7 & 894 & 0,012 & 17 & 837 & 0,018 \\
\hline 8 & 980 & 0,010 & 18 & 1011 & 0,017 \\
\hline 9 & 973 & 0,011 & 19 & 904 & 0,008 \\
\hline 10 & 944 & 0,005 & 20 & 822 & 0,022 \\
\hline
\end{tabular}


Под действием ядерных излучений существенно падает магнитная проницаемость, нарушается зонная структура полупроводников и диэлектриков, увеличивается коэрцитивная сила, электросопротивление изменяется в пределах десятков процентов.

Эксперимент проводился с помощью исследовательского реактора ИР-200, максимальной тепловой мощностью 200 кВт. ИР-200 - реактор бассейнового типа, корпус имеет диаметр 1800 мм, высоту 4400 мм. Активная зона размещена в нижней части корпуса и состоит из семистерженьковых кассет. Тепловыделяющие элементы изготовлены из двуокиси урана обогащением $10 \%$, диаметр 10 мм, высота 500 мм.

Для первой серии экспериментов определены следующие значения плотностей потоков нейтронов (таблица 5).

При этом считаем: $\Phi_{\text {Б }}$ с энергией $>0,6$ МЭВ, $\Phi_{\text {пр }}-0,625-0,6$ мэВ, $\Phi_{\text {т }}-<0,625$ мэВ. Коэффициент неравномерности нейтронного потока по высоте измерительной ампулы $K_{z}=I$. Максимальная ошибка в определении плотности потоков нейтронов $15 \%$. При относительно небольшом времени облучения (до 1000 часов) основную роль в образовании радиационных дефектов играют нейтроны с энергиями более 0,6 МЭВ (быстрые нейтроны).
Расчет необходимого времени облучения при работе реактора на полной мощности учитывает именно эту составляющую спектра нейтронов. При облучении в центральном экспериментальном канале до $\Phi=10^{18} \mathrm{H} / \mathrm{cm}^{2}$, необходимое время облучения (время работы аппарата):

$$
t_{\text {обл }}=\frac{10^{18}}{10^{12}}=10^{6} \mathrm{c} \approx 280 \text { часов. }
$$

При облучении в вертикальном канале №1

$$
t_{\text {обл }}=\frac{10^{18}}{0,1 \cdot 10^{12}}=10^{7} \mathrm{c} \approx 2800 \text { часов. }
$$

По условиям работы облучение образцов будем производить до появления заметных отклонений от номинала, учитывая фактические условия работы исследуемых элементов в более слабых потоках, чем в активной зоне реактора.

Результаты измерения электрического сопротивления $R$ образцов на первом этапе исследования приведены в таблице 6 (до облучения).

Образцы облучались в вертикальном канале на протяжении 30 часов. Результаты облучения в пределах флюенса по нейтронам $7,2 \cdot 10^{16} \div 10^{17}$ представлены в таблице 7.

Таблица 5.

Значение плотностей потоков нейтронов

\begin{tabular}{|c|c|c|c|}
\hline Канал/Поток & $\Phi_{\mathrm{b}} \cdot 10^{-12}$ & $\begin{array}{c}\Phi_{\text {пр }} \cdot 10^{-12} \\
\text { нейтр } /\left(\mathrm{cm}^{2} \cdot \mathrm{c}\right)\end{array}$ & $\begin{array}{c}\Phi_{\mathrm{T}} \cdot 10^{-12} \\
\text { нейтр } /\left(\mathrm{cm}^{2} \cdot \mathrm{c}\right)\end{array}$ \\
\hline ЦЭК & 0,95 & 0,36 & 0,9 \\
\hline ВЭК & 0,14 & 0,3 & 0,4 \\
\hline
\end{tabular}

Таблица 6.

Результаты измерения электросопротивления образцов до облучения

\begin{tabular}{|c|c|c|c|c|c|c|c|c|c|c|}
\hline № образца & 1 & 2 & 3 & 4 & 5 & 6 & 7 & 8 & 9 & $10^{*}$ \\
\hline$R$, Ом & 4,56 & 4,63 & 3,49 & 4,90 & 5,0 & 5,2 & 5,84 & 5,9 & 5,9 & $2 \cdot 10^{11}$ \\
\hline
\end{tabular}

*электросопротивление пьезокерамики

Таблица 7.

Результаты измерения электросопротивления образцов после облучения

\begin{tabular}{|c|c|c|c|c|c|c|c|c|c|c|}
\hline № образца & 1 & 2 & 3 & 4 & 5 & 6 & 7 & 8 & 9 & $10^{*}$ \\
\hline$R$, Ом & 4,6 & 4,66 & 3,50 & 4,94 & 5,5 & 5,7 & 6,4 & 6,8 & 6,8 & $2 \cdot 10^{11}$ \\
\hline
\end{tabular}

*электросопротивление пьезокерамики 
Электросопротивление проводниковых пленок незначительно увеличивается при облучении флюенсами до $10^{17}$, при этом относительное отклонение уменьшается с уменьшением величины номинала. Емкость и $\operatorname{tg} \delta$ пьезокерамики остается без изменений в испытываемом диапазоне, и составляют соответственно 73 пФ, 20·10-4.

\section{Выводы}

Исследование электрофизических свойств материалов для гибридных интегральных схем, работающих в системах обслуживания ядерных энергетических установок, целесообразно выполнять экспериментальным путем в условиях, максимально приближенных к реальным.
Наиболее полную информацию об изменении электрофизических свойств исследуемых образцов можно получить в случае, когда есть возможность измерять определяющие параметры и их эволюцию для образцов, длительное время находящихся в поле облучения.

\section{References}

1. Марковский, Е.А., Краснощеков, М.М., Тихонов, B.И. Воздействие ядерных излучений на структуру и свойства металлов и сплавов. - Киев: Наукова думка. - 1968. - 334 с.

2. Динс, Джс, Винйард, Дж. Радиационные эффекты в твердых телах. - Москва: ИИП. - 1960. $275 \mathrm{c}$. 